\title{
A Physiologic Role for Somatostatin 28 as a Regulator of Insulin Secretion
}

\author{
David A. D'Alessio, Cornel Sieber," Christoph Beglinger," and John W. Ensinck \\ Department of Medicine, University of Washington, Seattle, Washington 98195; and *Division of Gastroenterology \\ and Department of Research, University Hospital, CH-4031 Basel, Switzerland
}

\begin{abstract}
Somatostatin 28 (S-28) is a peptide produced in the intestinal tract which rises in the circulation during nutrient absorption. We tested the hypothesis that S-28 regulates B-cell function by (a) studying the effects on insulin secretion of "physiologic" infusions of S-28 and $(b)$ measuring insulin responses during elevated nutrient-stimulated endogenous S-28 levels. (a) Synthetic S-28 was infused on separate days into six healthy men at rates of 25 and $50 \mathrm{ng} / \mathrm{kg}$ per $\mathrm{h}$ which mimicked postprandial levels. Subjects were given a bolus of glucose $(0.1 \mathrm{~g} / \mathrm{kg})$ after $120 \mathrm{~min}$. Insulin responses during S-28 infusions were compared to a control study using a saline infusion in the same individuals. Glucose-stimulated insulin secretion was inhibited during the infusion of $50 \mathrm{ng} / \mathrm{kg}$ per $\mathrm{h}$ S-28 when compared to control $(P<0.05)$. (b) Insulin secretion during elevations of endogenous S-28 was studied in healthy men who received a bolus of $2.5 \mathrm{~g}$ arginine $(n=14)$ or $25 \mathrm{U}$ of secretin $(n=8) 120$ min after swallowing $50 \mathrm{~g}$ fat, or, on a separate day, an equivalent volume of water. S-28 levels rose significantly after fat ingestion but did not change after water. Arginine and secretin-stimulated insulin secretion was inhibited following ingestion of fat compared with intake of water $(P<0.05)$. Arginineenhanced glucagon secretion was not changed by fat ingestion. We conclude that elevations in plasma S-28 levels, occurring during the postprandial state, attenuate B-cell secretion and this peptide may be a physiologic modulator of nutrient-stimulated insulin release.
\end{abstract}

\section{Introduction}

It has been established that cells in the pancreas and gastrointestinal tract synthesize pro-somatostatin (pro-S) ${ }^{1}$ from which are derived two biologically active products, somatostatin 14 (S-14) and somatostatin 28 (S-28) (1-3). The processing of pro-S is tissue-specific with D cells in the pancreas and stomach and some enteric neurons synthesizing S-14 and specialized intestinal epithelial cells producing S-28 (4-6). Although recent work has provided evidence that $\mathrm{S}-14$ acts as a paracrine mediator of gastrin secretion in the stomach and glucagon

Part of this study was presented at the 48th Annual Meeting of the American Diabetes Association, New Orleans, LA, in June 1988.

Address reprint requests to Dr. Ensinck, Department of Medicine, RC-14, University of Washington, Seattle, WA 98195.

Received for publication 31 January 1989 and in revised form 12 April 1989.

1. Abbreviations used in this paper: pro-S, pro-somatostatin; S-14 and S-28, somatostatins 14 and 18 .

J. Clin. Invest.

(C) The American Society for Clinical Investigation, Inc.

0021-9738/89/09/0857/06 \$2.00

Volume 84, September 1989, 857-862 secretion in the pancreatic islet (7-9), no physiologic role for S-28 has yet been proven.

Several studies have documented a rise in somatostatinlike immunoreactivity after nutrient intake (10-13), and fat has been shown to be the most potent nutrient stimulus to somatostatin-like immunoreactivity release $(12,13)$. We have recently reported that, in healthy men, ingestion of a mixed meal results in a two- to threefold rise in S-28, without changes in S-14 (14). These data suggest that nutrients, particularly fat, stimulate intestinal epithelial cells to release S-28, and we postulate that this peptide may act as a hormone.

In pharmacologic amounts, both S-14 and S-28 suppress glucagon and insulin secretion (15-17). However, S-28 is the more potent inhibitor of pancreatic $B$ cells and binds to them more avidly than to A cells $(15,18,19)$. Conversely, S-14 binds to and inhibits A cells preferentially $(15,19)$. Pancreatic D cells are interspersed with A cells in the islet mantle, an anatomical arrangement well suited to paracrine regulation. Because islet blood flow is outward from the B-cell core to the A and D cells on the periphery $(20,21)$, it is unlikely that secretion of S-14 by pancreatic D cells influences B-cell function significantly. It is possible, however, that B-cell function is affected by circulating S-28 and that the rise in concentration of S-28 after a meal is involved in enteroinsular regulation.

We have observed that, when perfused through the isolated rat pancreas in concentrations similar to those found in postprandial humans, S-28 preferentially inhibited the glucosemediated first phase of insulin secretion with no effect on the second phase (Ensinck, J. W., unpublished observation). Therefore, we have used this finding to examine the hypothesis that $\mathrm{S}-28$ is a hormonal mediator of B-cell function by measurement of first-phase insulin secretion under two conditions: $(a)$ infusion of S-28 in physiologic concentrations and $(b)$ elevation of endogenous $\mathrm{S}-28$ by the ingestion of fat.

\section{Methods}

\section{Subjects}

Six healthy men, aged $21-30 \mathrm{yr}$, within $10 \%$ of ideal body weight, volunteered for the S-28 infusion protocol. They were free of chronic medical diseases and were not receiving medication. Each subject signed a written consent which was approved by the Basel University ethics committee.

22 healthy men, aged $20-47 \mathrm{yr}$, participated in the protocols involving intake of fat. They were free of chronic medical diseases and not receiving medication. Body weights were $68-114 \mathrm{~kg}$. Each subject signed a written consent for the studies which were approved by the human subjects committee at the University of Washington.

\section{Protocols}

$S$ - 28 concentrations after oral fat. Five volunteers were admitted to the University of Washington Clinical Research Center after an overnight fast. An antecubital vein was cannulated and attached to a three-way stopcock to allow repeated blood sampling. An intravenous line was kept patent with a slow infusion of $150 \mathrm{mM} \mathrm{NaCl}$. Blood samples were 
obtained at $-20,-15,-10$, and $0 \mathrm{~min}$. At time 0 , the subjects swallowed $162 \mathrm{ml}$ of cream (composition: $63 \% \mathrm{H}_{2} \mathrm{O}, 31 \%$ fat, $3 \%$ carbohydrate, $2 \%$ protein) containing $50 \mathrm{~g}$ of fat. Blood was collected at 30,60 , $90,120,180$, and $240 \mathrm{~min}$ and plasma was processed for S-28 measurements.

Insulin secretion during $S-28$ infusion. Six men were admitted to the research unit at Basel University after an overnight fast on three separate occasions. S-28 (Peninsula Laboratories, Inc., San Carlos, CA) was dissolved in $0.2 \%$ bovine serum albumin (BSA) for infusion. Subjects had antecubital veins cannulated on both arms: one for repeated blood sampling and the other for the infusion of $150 \mathrm{mM}$ saline, S-28, and glucose. On separate days, in random assignment, each subject received either $(a)$ saline, $(b) \mathrm{S}-28$ in $0.2 \% \mathrm{BSA}$ at $25 \mathrm{ng} / \mathrm{kg}$ per h, or $(c)$ $\mathrm{S}-28$ in $0.2 \%$ BSA at $50 \mathrm{ng} / \mathrm{kg}$ per h. Infusions were started at time 0 and blood sampled at $0,60,70,90$, and $120 \mathrm{~min}$. At $120 \mathrm{~min}$ an intravenous bolus of glucose $(0.1 \mathrm{~g} / \mathrm{kg})$ was administered over $20 \mathrm{~s}$. Blood was collected at 122,123,125,127, 130,135, 150, 165, and 180 min, and all samples were processed for measurement of plasma insulin and S- 28 concentrations.

Hormonal responses to secretin and arginine during absorption of fat. 22 healthy men were admitted to the University of Washington Clinical Research Center after an overnight fast on two separate occasions. An antecubital vein was cannulated and attached to a three-way stopcock to allow repeated blood sampling; patency of the line was maintained with $150 \mathrm{mM} \mathrm{NaCl}$. Blood was collected at $-15,-10,-5$, and $0 \mathrm{~min}$. The men then ingested either $162 \mathrm{ml}$ of cream $(50 \mathrm{~g}$ of fat) or $162 \mathrm{ml}$ of $\mathrm{H}_{2} \mathrm{O}$. Half of the volunteers received water and half received fat on the first day of the study. Blood samples were taken at $30,60,90,100,105,110$, and $115 \mathrm{~min}$. At $115 \mathrm{~min}, 2.5 \mathrm{~g}$ of arginine $(n$ $=14)$ or $25 U$ of secretin $(n=8)$ was injected intravenously over $120 \mathrm{~s}$. Blood was taken at 117,118,120,122,125, 130,145, and $160 \mathrm{~min}$, and samples were processed for measurement of plasma levels of insulin, glucagon, and S-28.

\section{Plasma measurements}

Blood was collected in heparinized tubes and centrifuged immediately after withdrawal, and the plasma was removed. To prevent proteasemediated destruction of S-28, aliquots were acidified to $\mathrm{pH} 3$ by addition of $1 \mathrm{~N} \mathrm{HCl}(0.1 \mathrm{ml} / \mathrm{ml}$ plasma $)$ and stored at $-20^{\circ} \mathrm{C}$. S- 28 levels were measured as described previously (14). Briefly, acidified samples were passed through octadecylsilyl silica cartridges (SepPak C-18, Waters Associates, Milford, MA), and plasma proteins and enzymes were removed by serial washing with absolute methanol and deionized water. Adsorbed peptides were eluted with $80 \%$ methanol, $1 \%$ trifluoroacetic acid solution, air-dried, and reconstituted in $130 \mathrm{mM}$ borate buffer. The sample was then applied to a column of agarose coupled with partially purified immunoglobulins selectively binding the $\mathrm{NH}_{2}$ region of S-28. The column was washed with $130 \mathrm{mM}$ borate buffer in which S-14 and pro-S were eluted. S-28 bound to the immunoadsorbent was eluted with $0.2 \mathrm{~N} \mathrm{HCl}$ and $0.2 \%$ BSA (Miles-Pentex, Kankakee, IL), pH 3.5, lyophilized, and dissolved in $130 \mathrm{mM}$ borate buffer.

Reconstituted samples were assayed for S-28 concentrations by radioimmunoassay (RIA) using an antiserum (AS-10), recognizing both S-14 and S-28. Assays were carried out in $130 \mathrm{mM}$ borate buffer with the antiserum diluted to $1: 100,000$ using Tyr-11-125I-S-14 as tracer. Free and antibody-bound labeled peptides were separated by addition of $1 \mathrm{ml}$ of $1 \%$ activated charcoal (Norit A, Eastman-Kodak Co., Rochester, NY). Values were obtained by comparison with the displacement of an S-28 standard. The measurements were corrected for recoveries of $50 \%$ when passed through the SepPak and immunoadsorbent (14). Plasma concentrations of S-28 after infusions of synthetic S-28 were measured by passing acidified plasma through SepPak cartridges and assaying the reconstituted peptides by RIA with AS-10 using a standard curve generated by S-28. Recoveries of S-28 from SepPak were $78 \%$ (14) and the measurements were appropriately corrected. Insulin and glucagon levels were measured by previously published methods $(22,23)$.

\section{Data analysis}

Insulin, glucagon, and S-28 values are presented as mean \pm SEM. The secretion of endogenous peptides stimulated by arginine, secretin, and glucose was calculated by summing the levels of hormone concentrations from 0-10 min and subtracting them from basal levels which were calculated as the mean of the four presecretagogue hormone values.

The hormonal responses to arginine and secretin were expressed as a percentage of basal concentrations to normalize for variation in basal hormone levels. The signed-ranks test, paired $t$ test, analysis of variance for repeated measures, and multiple and linear regression were used to analyze the data.

\section{Results}

Somatostatin- 28 concentrations after oral fat. The concentrations of S-28 before and after intake of $50 \mathrm{~g}$ of fat in healthy men are shown in Fig. 1. Mean plasma levels of S-28 rose from a baseline of $20 \mathrm{pg} / \mathrm{ml}$ to a peak of $56 \mathrm{pg} / \mathrm{ml}$ at $90 \mathrm{~min}$ that was sustained for the ensuing $90 \mathrm{~min}$. The mean rise in S-28 concentrations at $120 \mathrm{~min}$ was $35 \mathrm{pg} / \mathrm{ml}(P<0.05$ compared with basal).

Effect of infused S-28 on insulin secretion. Plasma S-28 concentrations during the infusions of saline and S-28 in six men are shown in Fig. 2. The increments in S-28 achieved with the 25 and $50 \mathrm{ng} / \mathrm{kg}$ per $\mathrm{h}$ infusions bracketed the range of S-28 levels attained after the ingestion of $50 \mathrm{~g}$ of fat. The mean values at $50 \mathrm{ng} / \mathrm{kg}$ per h were stable at $\sim 40 \mathrm{pg} / \mathrm{ml}$ above basal throughout $180 \mathrm{~min}$, whereas, during the infusion with 25 $\mathrm{ng} / \mathrm{kg}$ per $\mathrm{h}$, the levels oscillated between 10 and $25 \mathrm{pg} / \mathrm{ml}$ above preinfusion levels.

Basal insulin concentrations (60-120 min) were not different during the infusions of saline or S-28. The mean insulin responses $(n=6)$ to bolus injections of glucose during the saline and S-28 infusions are shown in Fig. 3. There was a decrease in mean insulin responses during both $\mathrm{S}-28$ infusions. The $50 \mathrm{ng} / \mathrm{kg}$ per $\mathrm{h}$ dose, which resulted in plasma S-28 levels comparable to those seen after fat intake, caused a significant decrease in insulin secretion $(P<0.05)$. Fig. 4 shows the relationship between the incremental changes in S-28 concentrations resulting from the S-28 infusions, and the differences in glucose-stimulated insulin secretion compared with the saline infusion. There was a significant correlation $(r=-0.69 ; P$

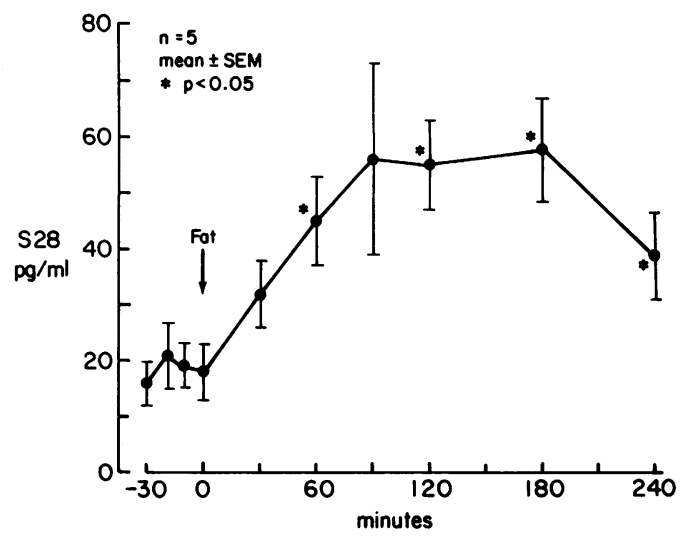

Figure 1. Plasma somatostatin-28 ( $S 28)$ concentrations in five men after the ingestion of $162 \mathrm{ml}$ of whipping cream containing $50 \mathrm{~g}$ of fat. Data points represent mean values \pm SEM. *Significantly different points $(P<0.05)$ compared with baseline. 


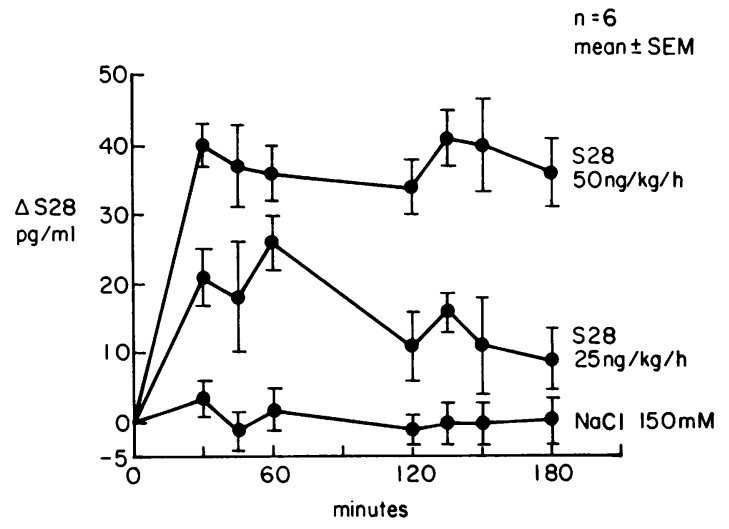

Figure 2. Increments in plasma somatostatin-28 $(S 28)$ concentrations above basal levels in six men during the infusions of $150 \mathrm{mM}$ saline or 25 and $50 \mathrm{ng} / \mathrm{kg}$ per h S28. Each data point is the mean \pm SEM.

$<0.02$ ) between the magnitudes of increase in S-28 concentrations and decrease in glucose-stimulated insulin secretion.

Effects of fat intake on arginine and secretin-stimulated insulin secretion. Mean plasma concentrations of insulin and glucagon throughout both the fat and water study periods for the arginine protocol are displayed in Table I. Postabsorptive values of insulin and glucagon were not different during the 2 $\mathrm{d}$ of study (data not shown). Basal concentrations of insulin and glucagon rose after fat intake to levels significantly greater than those after water ingestion. S-28 concentrations increased significantly after the fat (mean increment at 120 min was 21 $\mathrm{pg} / \mathrm{ml}$ ) but did not change after water (Table I).

In Figs. $5 \mathrm{~A}$ and 6 are shown the mean arginine-stimulated insulin and glucagon responses after water or fat ingestion. Arginine-stimulated insulin secretion was diminished by an average of $50 \%$ on the day the subjects drank cream compared with that on the day they had water. Glucagon secretion after arginine was not different during the $2 \mathrm{~d}$ of study.

Mean plasma concentrations of insulin during the secretion protocol are given in Table I. Postabsorptive values of insulin on the days of water and fat ingestion were not different (data not shown). Insulin concentrations rose after the intake of fat to levels significantly greater than on the control day. S-28 concentrations increased after ingestion of fat (mean increment at $120 \mathrm{~min}$ was $21 \mathrm{pg} / \mathrm{ml}$ ) to levels twofold greater than basal (Table I) but did not change after water intake.

Fig. $5 B$ shows the mean values for the amounts of insulin released by secretin in the eight men after fat and water ingestion, respectively. After the secretin infusion the rise in insulin

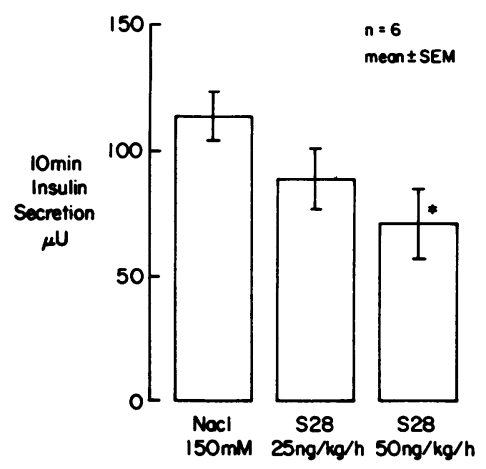

Figure 3. Insulin secretion after the bolus injection of glucose $(0.1 \mathrm{~g} / \mathrm{kg})$ in six men receiving infusions of saline or S-28. Each bar represents the mean \pm SEM of the increase in insulin concentrations above basal levels in the $10 \mathrm{~min}$ after administration of glucose. *Significantly different from saline $(P<0.05)$.

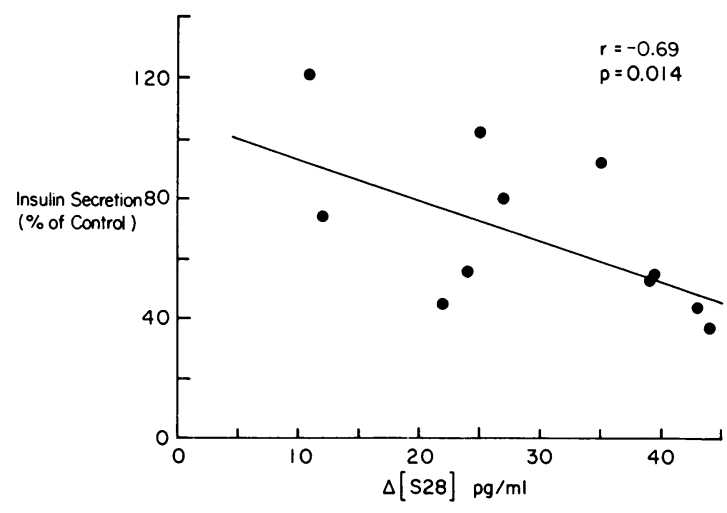

Figure 4. Correlation of decrements in glucose-stimulated insulin secretion with increments in plasma somatostatin-28 $(S 28)$ during infusions of S-28. Points represent the results of 6 men studied during administration of 25 and $50 \mathrm{ng} / \mathrm{kg}$ per h S-28.

concentrations was less after fat than after water $(P<0.05)$. As with arginine, insulin secretion was diminished $\sim 50 \%$ on the day of fat ingestion.

\section{Discussion}

These studies address the possible role of S-28 as a physiologic modulator of insulin secretion. We have tested this question by measuring insulin release during $(a)$ infusions of S-28 to mimic levels achieved after the oral intake of nutrient (fat) and (b) postprandial rises of endogenous S-28. The data presented here show that exogenous S-28 significantly inhibited firstphase insulin secretion induced with glucose and that insulin release evoked by first-phase secretagogues was reduced when endogenous S-28 levels were elevated. These results suggest that S-28 may be a physiologically relevant hormone.

Previous studies in which somatostatins have been infused into humans to assess their effects on islet function, have used either pharmacologic amounts of S-14 or S-28 $(16,17,24,25)$, or have not simulated physiologic conditions. Because S-14 does not rise significantly after meals, the results with infusions of this peptide to match postprandial increases in somatostatin-like immunoreactivity are not physiologically relevant. We used infusions of S-28 calculated to reproduce the circulating levels of this peptide measured after ingestion of fat or a mixed meal (14). We noted some variation in the plasma concentrations of S-28 achieved despite adjusting the infusions for body size, possibly reflecting differences in the clearance of S-28. However, individuals with the highest increments of S-28 after intravenous administration had the greatest attenuation of first-phase insulin secretion. The strong correlation between the decrement in stimulated insulin secretion with increments in S-28 concentrations, which coincide with levels seen after fat intake, is in keeping with the interpretation that insulin release is attenuated by S-28 levels occurring under physiologic conditions.

Ingestion of fat resulted in increases in circulating S-28 similar to those previously described following a mixed meal (14). We fed fat alone to avoid an elevation of blood glucose and its interaction with "incretins" to stimulate insulin secretion. Accordingly, arginine and secretin rather than glucose were used to stimulate insulin secretion. Nonetheless, small 
Table I. Peptide Concentrations During the Arginine, Secretin, and S-28 Infusion Protocols

\begin{tabular}{|c|c|c|c|c|c|c|c|c|}
\hline & \multicolumn{2}{|c|}{ S-28 } & \multicolumn{3}{|c|}{ Insulin } & \multicolumn{3}{|c|}{ Glucagon } \\
\hline & Basal & $120 \min$ & Basal & Increment & $\%$ Basal & Basal & Increment & \% Basal \\
\hline & \multicolumn{2}{|c|}{$p g / m l$} & \multicolumn{3}{|c|}{$\mu U / m l$} & \multicolumn{3}{|c|}{$p g / m l$} \\
\hline \multicolumn{9}{|l|}{ Arginine $(n=14)$} \\
\hline $\mathrm{H}_{2} \mathrm{O}$ ingestion & $27 \pm 3$ & $25 \pm 2$ & $7 \pm 1$ & $104 \pm 14$ & $1,875 \pm 269$ & $35 \pm 2$ & $198 \pm 31$ & $574 \pm 79$ \\
\hline Cream ingestion & $33 \pm 4$ & $54 \pm 6^{*}$ & $11 \pm 2^{*}$ & $86 \pm 8$ & $953 \pm 112^{*}$ & $43 \pm 3$ & $233 \pm 26$ & $568 \pm 75$ \\
\hline \multicolumn{9}{|l|}{ Secretin $(n=8)$} \\
\hline $\mathrm{H}_{2} \mathrm{O}$ ingestion & $22 \pm 3$ & $21 \pm 3$ & $7 \pm 1$ & $70 \pm 12$ & $1,246 \pm 308$ & & & \\
\hline Cream ingestion & $22 \pm 3$ & $43 \pm 12^{*}$ & $10 \pm 1^{*}$ & $41 \pm 6^{*}$ & $445 \pm 78^{*}$ & & & \\
\hline \multicolumn{9}{|l|}{ S-28 infusion } \\
\hline Saline & $42 \pm 5$ & $41 \pm 3$ & $7 \pm 1$ & $114 \pm 22$ & $1,711 \pm 246$ & & & \\
\hline $25 \mathrm{ng} / \mathrm{kg}$ per $\mathrm{h}$ & $48 \pm 6$ & $57 \pm 7$ & $6 \pm 1$ & $89 \pm 28$ & $1,634 \pm 277$ & & & \\
\hline $50 \mathrm{ng} / \mathrm{kg}$ per $\mathrm{h}$ & $42 \pm 6$ & $74 \pm 5^{*}$ & $6 \pm 1$ & $71 \pm 30^{*}$ & $1,271 \pm 194$ & & & \\
\hline
\end{tabular}

S-28 data from the arginine and secretin protocols are from $n=10$ and 6 , respectively. ${ }^{*} P<0.05$ compared with control.

but distinct increases in basal insulin levels were noted after subjects swallowed cream. This was probably due to the insulinotropic effect of other gut factors stimulated by fat (26). Despite this, first-phase insulin secretion was decreased with S-28 levels were increased. The concurrence of these results with those of the S-28 infusions suggests that the increase of S-28 causes B-cell inhibition.

Elevations of plasma S-28 did not alter basal or argininestimulated A-cell secretion of glucagon. These results are in agreement with those of in vitro studies which also demonstrate a relatively greater effect of S-28 on pancreatic B cells $(15,19)$. Recently, an inhibitory effect of elevated postprandial S-28 levels on pancreatic exocrine secretion has been reported (P. Hildebrand, unpublished observation), so it is likely that the effects of S-28 released during nutrient absorption are not restricted to the pancreatic B-cell.

During the infusion of S-28 in our subjects, basal levels of insulin were not decreased. Klaff et al. (27) have recently reported similar findings with infusions of S-28 into the canine pancreas which mimic physiologic increases of SLI after nutrients, and concluded that S-28 does not regulate islet cell

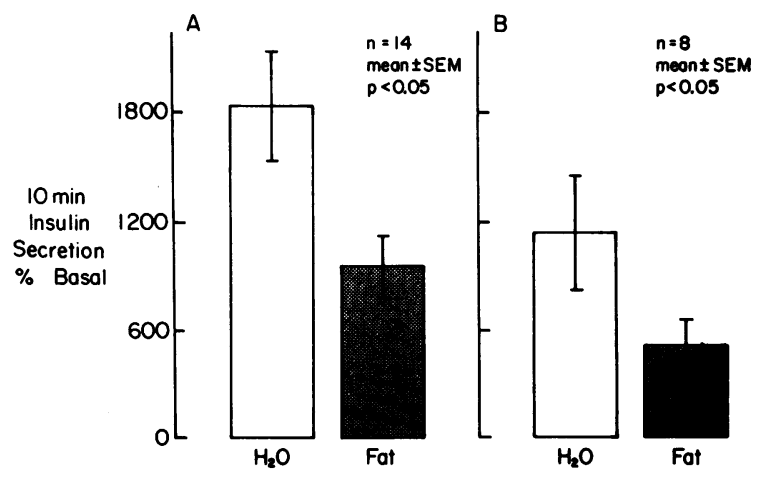

Figure 5. (A) Insulin secretion following an intravenous bolus of 2.5 $\mathrm{g}$ of arginine in $14 \mathrm{men} 120 \mathrm{~min}$ after oral intake of $162 \mathrm{ml}$ of whip ping cream $(50 \mathrm{~g}$ of fat) or water. Bars represent the mean \pm SEM of increases in insulin as a percentage of basal levels in the $10 \mathrm{~min}$ after injection. (B) Insulin secretion following an intravenous bolus of 25 $U$ of secretin in eight men after fat or water ingestion. function in the dog. However, their studies did not test the effects of S-28 on stimulated insulin secretion. As indicated by our results insulin secretion stimulated by arginine, secretin, or glucose was diminished in the presence of elevated S-28 concentrations. Thus, the effect of increased circulating S-28 on B cells was independent of the secretagogue studied, and may reflect a specific inhibitory action on the process of first-phase insulin secretion. Because the experimental design involved only the evaluation of first-phase insulin secretion, we cannot comment on second-phase release. However, it has previously been reported that at supraphysiologic levels S-14 selectively inhibits first-phase insulin release in vitro (28) and we have recently made a similar observation using periphysiologic levels of S-28 in the isolated rat pancreas (Ensinck, J. W., unpublished observation). It is possible, therefore, that S-28 modulates the glucose threshold for the release of the pool of stored insulin which is thought to constitute first phase $(29,30)$.

The concept and rationale for a "decretin," a nutrientstimulated inhibitor of insulin secretion, is not intuitively obvious. The role of insulin as the cardinal anabolic hormone and its mediation of postprandial nutrient disposal are well established. However, the control of insulin secretion is complex and involves the interplay of a variety of factors. Insulin secretion is only partially dependent on caloric intake (31) and plasma glucose concentrations (32). Although no single factor yet described totally accounts for the "incretin" effect after oral glucose (26), it is likely that peptides originating in the gastrointestinal tract stimulate insulin secretion. Cholecyto-

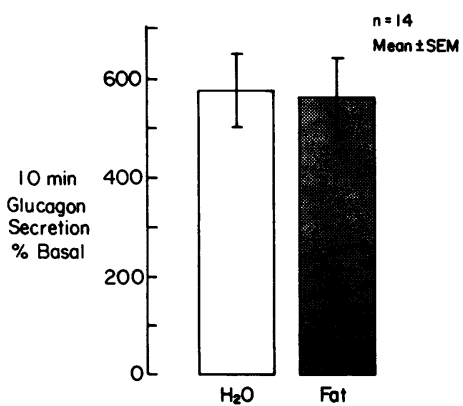

Figure 6. Glucagon secretion after an intravenous bolus of $2.5 \mathrm{~g}$ of arginine in 14 men 120 min after 162 $\mathrm{ml}$ of whipping cream $(50 \mathrm{~g}$ of fat) or water. Data are shown as the mean \pm SEM of incremental increases in glucagon as a percentage of basal levels in the $10 \mathrm{~min}$ after arginine injection. 
kinin potentiates insulin release in the presence of amino acids (33), gastric inhibitory polypeptide has a demonstrated glucose-dependent insulinotropic activity (36), and GLP-1(7-36), a product of pro-glucagon released by ileal epithelium, has potent B-cell stimulatory effects in vitro (35) and in vivo (36). The interaction of these gut factors with each other and the neural influences on insulin. secretion (37) have not been clarified. In such a complex system S-28 may act to fine-tune insulin secretion, a counterweight to the many B-cell stimuli, particularly during latter stages of absorption where glucose has been assimilated and the need for insulin is waning. It is conceivable that the attenuating effects of S-28 on insulin secretion act to smooth the secretory response and prevent excessive fluctuations in plasma insulin and glucose levels.

In summary, we have shown that after the ingestion of fat there is a rise in circulating S-28 concentrations and an associated decrement in first-phase insulin release. Infusion of S-28 to similar levels results in comparable inhibition of B-cell secretion. We conclude that the increased levels of circulating S-28 attained during nutrient absorption modulates insulin secretion.

\section{Acknowledgments}

We thank Ms. Beverly Alexander for her assistance with preparation of the manuscript, and Ms. Ellen Laschansky and Ms. Robin Vogel for their excellent technical assistance.

This work was supported by U. S. Public Health Service grant R01-DK34397, Program Project grant AM02456, Metabolism and Endocrinology Training Grant AM07247, and Diabetes Endocrinology Research Center AM17047, and grants from the American Diabetes Association, Juvenile Diabetes Foundation, The Sugar Association, Inc., and Swiss National Science Foundation (grant 3.890-0.88). A portion of this work was conducted through the Clinical Research Center facility of the University of Washington supported by the National Institutes of Health, grant RR-37.

\section{References}

1. Reichlin, S. 1983. Somatostatin. N. Engl. J. Med. 309:14951500; 1556-1563.

2. Shoelson, S., K. Polonsky, T. Nakabuyashi, J. Jaspan, and H. Tager. 1986. Circulating forms of somatostatin-like immunoreactivity in human plasma. Am. J. Physiol. 250:E428-434.

3. Patel, Y., T. Wheatley, and C. Ning. 1981. Multiple forms of immunoreactive somatostatin: comparison of distribution in neural and nonneural tissues and portal plasma of the rat. Endocrinology. 109:1943-1949.

4. Ravazzola, M., R. Benoit, N. Ling, R. Guillemin, and L. Orci. 1983. Immunocytochemical localization of prosomatostatin fragments in maturing and mature secretory granules of pancreatic and gastrointestinal D cells. Proc. Natl. Acad. Sci. USA. 80:215-218.

5. Baldiserra, F., J. Holst, L. Steen, and T. Krarup. 1985. Distribution and molecular forms of peptides containing somatostatin immunodeterminants in extracts from the entire gastrointestinal tract of man and pig. Biochim. Biophys. Acta. 838:132-143.

6. Chiba, T., J. Park, and T. Yamada. 1988. Biosynthesis of somatostatin in canine fundic D cells. J. Clin. Invest. 81:282-287.

7. Larsson, I., N. Goltermann, and L. Magistras. 1979. Somatostatin cell processes as pathways for paracrine secretion. Science (Wash. DC). 205:1393-1395.

8. Klaff, I., and G. Taborsky. 1987. Role of pancreatic somatostatin in determining glucagon response to arginine and morphine. Am. $J$. Physiol. 252:E751-E755.
9. Klaff, I., and G. Taborsky. 1986. Pancreatic somatostatin is a mediator of glucagon inhibition by hyperglycemia. Diabetes. 36:592596.

10. Zyznar, E., A. Pietri, V. Harris, and R. Unger. 1981. Evidence for the hormonal status of somatostatin in man. Diabetes. 30:883-886.

11. Polonsky, K., S. Shoelson, and H. Docherty. 1983. Plasma somatostatin 28 increases in response to feeding in man. J. Clin. Invest. 71:1514-1518.

12. Lucey, M., P. Fairclough, J. Wass, P. Kwasowski, S. Medbak, J. Webb, and L. Rees. 1984. Response of circulating somatostatin, insulin, gastrin and GIP to intraduodenal infusion of nutrients in normal man. Clin. Endocrinol. 21:209-217.

13. Penman, E., J. Wass, S. Medbak, L. Morgan, J. Lewis, G. Besser, and L. Rees. 1981. Response of circulating immunoreactive somatostatin to nutritional stimuli in normal subjects. Gastroenterology. 81:692-699.

14. Ensinck, J., E. Laschansky, R. Vogel, D. Simonowitz, B. Roos, and B. Francis. 1989. Circulating pro-somatostatin derived peptides: differential responses to food ingestion. J. Clin. Invest. In press.

15. Mandarino, L., D. Stenner, W. Blanchard, S. Nissen, J. Gerich, N. Ling, P. Brazwau, P. Bohlen, F. Esch, and R. Guillemin. 1981. Selective effects of somatostatin-14, -25 , and -28 on in vitro insulin and glucagon secretion. Nature (Lond.). 291:76-77.

16. Marco, J., I. Correas, M. A. Zulatta, E. Vincent, D. Coy, A. Comaru-Schally, A. Schally, M. Rodriguez-Arnao, and A. GomezPan. 1983. Inhibitory effect of somatostatin-28 on pancreatic polypeptide, glucagon, and insulin secretion in man. Horm. Metab. Res. 15:363-366.

17. Konturek, S., N. Kweicien, W. Obtulowicz, W. Bielanski, J. Oleksy, and A. Schally. 1985. Effects of somatostatin-14 and somatostatin-28 on plasma hormonal and gastric secretory responses to cephalic and gastrointestinal stimulation in man. Scand. J. Gastroenterol. 20:31-38.

18. Meyers, C., W. Murphy, T. Redding, D. Coy, and A. Schally. 1980. Synthetic and biological actions of prosomatostatin. Proc. Natl. Acad. Sci. USA. 77:6171-6174.

19. Amberdt, M., Y. Patel, and L. Orci. 1987. Selective binding of somatostatin-14 and somatostatin-28 to islet cells revealed by quantitative electron microscopic autoradiography. J. Clin. Invest. 80:14551458.

20. Bonner-Weir, S., and L. Orci. 1982. New perspectives on the microvasculature of the islets of Langerhans in the rat. Diabetes. 31:883-889.

21. Samols, E., J. Stagner, R. Ewart, and V. Marks. 1988. The order of islet microvascular cellular perfusion is $B \rightarrow A \rightarrow D$ in the perfused rat pancreas. J. Clin. Invest. 82:350-353.

22. Zaharko, D., and L. Beck. 1968. Studies of a simplified plasma insulin immunoassay using cellulose powder. Diabetes. 17:444-457.

23. Ensinck, J., C. Shepard, R. Dudl, and R. Williams. 1971. Use of benzamidine as a proteolytic inhibitor in the radioimmunoassay of glucagon in plasma. J. Clin. Endocrinol. Metab. 35:463.

24. Gyr, K., C. Beglinger, E. Kohler, V. Trautzl, V. Keller, and S. Bloom. 1987. Circulating somatostatin: Physiological regulator of pancreatic function. J. Clin. Invest. 79:1595-1600.

25. Souquet, J., R. Rambliere, J. Riou, M. Beylot, R. Cohen, R. Mornex, and J. Chayvialle. 1983. Hormonal and metabolic effects of near physiological increase of plasma immunoreactive somatostatin 14. J. Clin. Endocrinol. Metab. 56:1076-1079.

26. Creutzfeldt, W., and R. Ebert. 1985. New developments in the incretin concept. Diabetologia. 28:565-573.

27. Klaff, L., B. Dunning, and G. Taborsky. 1988. Somatostatin-28 does not regulate islet function in the dog. Endocrinology. 123:26682674.

28. Curry, D., and L. Bennett. 1976. Does somatostatin inhibition of insulin secretion involve two mechanisms of action? Proc. Natl. Acad. Sci. USA. 73:248-251.

29. Grodsky, G. 1971. A threshold distribution hypothesis for 
packet storage of insulin and its mathematical modeling. J. Clin. Invest. 51:2047-2059.

30. Chen, M., and D. Porte. 1976. The effect of rate and dose of glucose infusion on the acute insulin response in man. J. Clin. Endocrinol. Metab. 42:1168-1175.

31. Polonsky, K., B. Given, and E. VanCauter. 1988. Twentyfour-hour profiles and pulsatile patterns of insulin secretion in normal and obese subjects. J. Clin. Invest. 81:442-448.

32. Smith, C., A. Tarn, J. Thomas, D. Overcamp, A. Coraki, M. Savage, and E. Gale. 1988. Between and within subject variation of the first phase insulin response to intravenous glucose. Diabetologia. 31:123-125.

33. Rushakoff, R., I. Goldfine, J. Carter, and R. Little. 1987. Physiological concentrations of cholecystokinin stimulate amino acid-in- duced insulin release in humans. J. Clin. Endocrinol. Metab. 65:395401.

34. Crockett, S., S. Cataland, J. Falko, and E. Mazzaferri. 1976. The insulinotropic effect of endogenous gastric inhibitory polypeptide in normal subjects. J. Clin. Endocrinol. Metab. 42:1098-1103.

35. Mojsov, S., G. Weir, and J. Habener. 1988. Insulinotropin: glucagon-like peptide 1 (7-37) co-encoded in the glucagon gene is a potent stimulator of insulin release in the perfused rat pancreas. $J$. Clin. Invest. 79:616-619.

36. Kreymann, B., M. Ghatei, G. Williams, and S. Bloom. 1987. Glucagon-like peptide-1 7-36: a physiological incretin in man. Lancet. 2:1300-1303.

37. Ahren, B., G. Taborsky, and D. Porte. 1986. Neuropeptidergic versus cholinergic and adrenergic regulation of islet hormone secretion. Diabetalogia. 29:827-836. 